\title{
PROVISION OF EMERGENCY BEDS IN HOSPITALS
}

\author{
BY \\ D. J. NEWELL \\ Nuffield Department of Industrial Health, King's College Medical School (University of Durham), \\ Newcastle-upon-Tyne
}

\section{(1) INTRODUCTION}

A number of beds are reserved each day in most hospitals to accommodate emergency cases arriving during the day. Since the number of emergency cases fluctuates considerably from day to day, it is not immediately obvious how many beds should be set aside for this purpose. If all the beds so reserved are filled during the day, any further emergency cases must either be accommodated in extra beds in the centre of a ward, or referred to another hospital. Neither of these expedients can be regarded as fully satisfactory. The former method involves extra duties for hospital staff, and the latter not only causes extra travelling for emergency cases, but also fails to guarantee a bed. In London, for example, where the transfer of applications for beds is very efficiently organized by the King Edward's Hospital Fund Emergency Bed Service, beds are not immediately available for 10 to 15 per cent. of the cases referred to the Service (Daley, 1953).

On the other hand, if a large number of emergency beds is provided to satisfy peak demands, many of them will remain empty on days of low demand. As emergency beds can only be reserved at the expense of the beds available for patients on the waiting list, wastage of this kind should be kept as low as possible. The problem thus resolves itself into balancing two opposing factors:

(i) the ratio of the number of emergency beds occupied to the number demanded, which we call $\mathrm{E}$, the efficiency factor,

(ii) the ratio of the number of emergency beds occupied to the number reserved for this purpose, called $F$, the occupation factor.

In Section 2, we set up a simple mathematical model of the demand pattern, and consider the relationship between $E$ and F. In Section 3, these theoretical results are compared with the actual demand figures recorded at a hospital.

\section{(2) Mathematical Model}

It has been found that where a large number of persons are subject to a small but constant risk of accident, the number of accidents in successive time-intervals varies according to a Poisson distribution. It is to be expected that in any set of time intervals in which the (small) probability of a patient requiring an emergency bed is constant, the demand for beds will also follow a Poisson distribution. That is, the probability of a demand for $r$ beds in a day is given by:

$$
p_{r}=e^{-m} m^{r} / r !
$$

where $m$ is the average daily demand.

Suppose $a$ beds are provided. Then, so long as $r \leqslant a$, a demand for $r$ beds can be fully satisfied, and $(a-r)$ beds will not be used. If, however, $r>a$ then all $a$ beds will be occupied, and $(r-a)$ patients must be accommodated elsewhere. Let the mean number of beds occupied be $b$.

$$
\text { Then } \begin{aligned}
b & =\sum_{r=0}^{a} r p_{r}+\sum_{r=a+1}^{\infty} a p_{r} \\
& =m \sum_{r=0}^{a-1} \frac{m^{r} e^{-m}}{r !}+a \sum_{r=a+1}^{\infty} \frac{m^{r} e^{-m}}{r !} \\
& =m\left\{1-\sum_{r=a}^{\infty} \frac{m^{r} e^{-m}}{r !}\right\}+a \sum_{r=a+1}^{\infty} \frac{m^{r} e^{-m}}{r !} \\
& =m\{1-P(a, m)\}+a P(a+1, m)
\end{aligned}
$$

where $P(c, m)=\sum_{r=c}^{\infty} \frac{m^{r} e^{-m}}{r !}$

Hence the efficiency of the scheme with mean demand $m$, and $a$ beds provided is:

$$
\mathrm{E}=\frac{b}{m}=1-P(a, m)+\frac{a}{m} P(a+1, m),
$$


and the occupation factor is:

$$
\mathrm{F}=\frac{b}{a}=\frac{m}{a}\{1-P(a, m)\}+P(a+1, m) .
$$

$P(c, m)$ is tabulated as the accumulated terms of Poisson's Exponential Binomial Limit (Molina, 1945).

It is clear that $\mathrm{E}=\mathrm{F}\left(=1-m^{m} e^{-m} / m !\right)$ when $m=a$, i.e., when the number of beds supplied is equal to the mean daily demand. This, however does not solve the problem, as a high efficiency should be regarded as the first desideratum, the occupation factor being somewhat less important.

Values of $\mathrm{E}$ and $\mathrm{F}$ can easily be computed from the Tables of $P(c, m)$. In Table I, they are shown for mean daily demands of $5,10,15,20,25$, and 30 , with various values of $a$ (the number of beds provided).

Example.-For a hospital with a mean daily demand for ten beds, the provision of twelve beds each day would mean that in the long run, a bed would be immediately available for 94.7 per cent. of the patients, and each bed would be occupied on $78 \cdot 9$ per cent. of the days.

TABLE I

EFFICIENCIES AND OCCUPATION FACTORS: THEORETICAL

\begin{tabular}{|c|c|c|c|}
\hline$\underset{m}{\text { Mean }}$ & $\begin{array}{c}\text { Daily } \\
\text { Provision } \\
a\end{array}$ & $\stackrel{\mathbf{E}}{\text { (per cent.) }}$ & $\begin{array}{c}\mathbf{F} \\
\text { (per cent.) }\end{array}$ \\
\hline 5 & $\begin{array}{r}5 \\
7 \\
8 \\
9 \\
10\end{array}$ & $\begin{array}{l}82 \cdot 5 \\
94 \cdot 9 \\
97 \cdot 6 \\
98 \cdot 9 \\
99 \cdot 6\end{array}$ & $\begin{array}{l}82 \cdot 5 \\
67 \cdot 8 \\
61 \cdot 0 \\
55 \cdot 0 \\
49 \cdot 8\end{array}$ \\
\hline 10 & $\begin{array}{l}10 \\
12 \\
13 \\
14 \\
15\end{array}$ & $\begin{array}{l}87 \cdot 5 \\
94 \cdot 7 \\
96 \cdot 8 \\
98 \cdot 1 \\
99 \cdot 0\end{array}$ & $\begin{array}{l}87 \cdot 5 \\
78 \cdot 9 \\
74 \cdot 4 \\
70 \cdot 1 \\
66 \cdot 0\end{array}$ \\
\hline 15 & $\begin{array}{l}15 \\
17 \\
18 \\
19 \\
20\end{array}$ & $\begin{array}{l}89 \cdot 8 \\
94 \cdot 9 \\
96 \cdot 6 \\
97 \cdot 8 \\
98 \cdot 6\end{array}$ & $\begin{array}{l}89 \cdot 8 \\
83 \cdot 6 \\
80 \cdot 5 \\
77 \cdot 2 \\
73 \cdot 9\end{array}$ \\
\hline 20 & $\begin{array}{l}20 \\
22 \\
23 \\
24 \\
25\end{array}$ & $\begin{array}{l}91 \cdot 1 \\
95 \cdot 1 \\
96 \cdot 5 \\
97 \cdot 6 \\
98 \cdot 4\end{array}$ & $\begin{array}{l}91 \cdot 1 \\
86 \cdot 5 \\
83 \cdot 9 \\
81 \cdot 3 \\
78 \cdot 7\end{array}$ \\
\hline 25 & $\begin{array}{l}25 \\
27 \\
28 \\
29 \\
30\end{array}$ & $\begin{array}{l}92 \cdot 1 \\
95 \cdot 3 \\
96 \cdot 5 \\
97 \cdot 5 \\
98 \cdot 2\end{array}$ & $\begin{array}{l}92 \cdot 1 \\
88 \cdot 3 \\
86 \cdot 2 \\
84 \cdot 0 \\
81 \cdot 8\end{array}$ \\
\hline 30 & $\begin{array}{l}30 \\
32 \\
33 \\
34 \\
35\end{array}$ & $\begin{array}{l}92 \cdot 7 \\
95 \cdot 5 \\
96 \cdot 6 \\
97 \cdot 4 \\
98 \cdot 1\end{array}$ & $\begin{array}{l}92 \cdot 7 \\
89 \cdot 5 \\
87 \cdot 8 \\
85 \cdot 9 \\
84 \cdot 1\end{array}$ \\
\hline
\end{tabular}

From this Table, the hospital administrator can determine how many beds should be provided to ensure an efficient service. If a standard of 95 per cent. efficiency is set (nineteen out of twenty emergency cases have a bed immediately available), the numbers $a$ of beds required, for different mean demands $m$ would be :

$\begin{array}{lcccccc}m & 5 & 10 & 15 & 20 & 25 & 30 \\ a & 7 & 12 & 17 & 22 & 27 & 32 \\ \text { F (\%) } & 67 \cdot 8 & 78 \cdot 9 & 83 \cdot 6 & 86 \cdot 5 & 88 \cdot 3 & 89 \cdot 5\end{array}$

If we set the standard of $E=97.5$ per cent. (only one in forty patients having to be accommodated elsewhere), the corresponding figures are:

$\begin{array}{ccccccc}m & 5 & 10 & 15 & 20 & 25 & 30 \\ a & 8 & 14 & 19 & 24 & 29 & 34 \\ \mathrm{~F} & 61 \cdot 0 & 70 \cdot 1 & 77 \cdot 2 & 81 \cdot 3 & 84 \cdot 0 & 86 \cdot 0\end{array}$

From these we deduce the simple result that whatever the mean demand between the limits 5 and 30 , a 95 per cent. efficiency can be achieved by providing two more beds than the mean demand, and a 97.5 per cent. efficiency by providing four more beds than the mean demand.

The increase of $\mathrm{F}$ with $m$ for fixed $\mathrm{E}$ shows that a hospital dealing with a large number of emergency cases has considerably less bed wastage than a number of smaller hospitals with the same efficiency. Thus 34 beds are needed to provide a 97.5 per cent. efficient service in one hospital with a mean daily demand for 30 beds, but 42 beds would be required to provide as efficient a service in each of three hospitals with mean demands of ten each.

\section{(3) Hospital Data}

Does the mathematical model fit the facts? Data of the demand for emergency beds each day were obtained from a hospital, and compared with the theory. The Royal Victoria Infirmary, Newcastleupon-Tyne, is a teaching hospital with 720 beds in 1950, drawing its patients from a wide area of North-East England. It can make the proud claim "we never refuse an emergency patient", a result achieved by setting up "centre-beds" whenever necessary. From a statistical point of view, this is very satisfactory, as the figures are unencumbered by possibly incomplete records of refused applications. There may be included a few cases accepted by this hospital after rejection by others, but as is usual with hospital data, it is impossible clearly to define the population served, and we must accept these cases as being proper to the teaching hospital.

A first analysis of the figures for each of the three years, 1950, 1951, and 1952, showed considerable divergence from the model. This was taken to indicate a change in the average demand. A complete analysis of the first year's figures showed that there was no significant difference in demand from month 
to month, but the demand on Sundays was significantly lower than that on weekdays. Accordingly, the Sunday figures were separated and found not to vary from year to year.

In Table II we show the distributions of demands for weekdays in each of the three years, and for Sundays in all three years together. The expected demands assuming the Poisson distribution are also shown. In none of the four distributions is there a significant divergence from the model, as indicated by the $\chi^{2}$ test.

TABLE II

HOSPITAL DATA : DISTRIBUTION OF DAILY DEMANDS OBSERVED AND EXPECTED VALUES

\begin{tabular}{|c|c|c|c|c|c|c|c|c|}
\hline \multirow{4}{*}{$\begin{array}{c}\text { Number } \\
\text { of } \\
\text { Beds } \\
\text { De- } \\
\text { manded }\end{array}$} & \multicolumn{8}{|c|}{ Frequency } \\
\hline & \multicolumn{6}{|c|}{ Weekdays } & \multirow{2}{*}{\multicolumn{2}{|c|}{$\begin{array}{c}\text { Sundays } \\
1950-2\end{array}$}} \\
\hline & \multicolumn{2}{|c|}{1950} & \multicolumn{2}{|c|}{1951} & \multicolumn{2}{|c|}{1952} & & \\
\hline & $\begin{array}{l}\text { Obs. } \\
\text { No. }\end{array}$ & Exp. & $\begin{array}{l}\text { Obs. } \\
\text { No. }\end{array}$ & Exp. & $\begin{array}{l}\text { Obs. } \\
\text { No. }\end{array}$ & Exp. & $\begin{array}{l}\text { Obs. } \\
\text { No. }\end{array}$ & Exp. \\
\hline $\begin{array}{r}4 \\
5 \\
6 \\
7 \\
8 \\
9 \\
10 \\
11 \\
12 \\
13 \\
14 \\
15 \\
16 \\
17 \\
18 \\
19 \\
20 \\
21 \\
22 \\
23 \\
24 \\
25 \\
26 \\
27 \\
28 \\
29 \\
30 \\
31 \\
32 \\
33 \\
34 \\
37 \\
38 \\
39\end{array}$ & $\left.\begin{array}{r}0 \\
0 \\
0 \\
2 \\
1 \\
3 \\
2 \\
2\end{array}\right\}$ & $\begin{array}{r}5.5 \\
8.5 \\
12.1 \\
16.1 \\
20.1 \\
23.7 \\
26.3 \\
27.7 \\
27.7 \\
26.4 \\
24.0 \\
20.9 \\
17.4 \\
13.9 \\
10.7 \\
7.9 \\
5.7\end{array}$ & $\left.\begin{array}{r}1 \\
0 \\
0 \\
0 \\
4 \\
2 \\
2\end{array}\right\}$ & $\begin{array}{r}7.7 \\
11.5 \\
15.9 \\
20.5 \\
24.6 \\
27.7 \\
29.3 \\
29.3 \\
27.8 \\
25.0 \\
21.4 \\
17.5 \\
13.7 \\
10.3 \\
7.4 \\
5.1\end{array}$ & $\left.\begin{array}{r}1 \\
0 \\
2 \\
0 \\
1 \\
2 \\
3\end{array}\right\}$ & $\begin{array}{r}5 \cdot 7 \\
\\
5 \cdot 1 \\
8 \cdot 1 \\
11 \cdot 9 \\
16 \cdot 1 \\
20 \cdot 4 \\
24 \cdot 3 \\
27 \cdot 1 \\
28 \cdot 6 \\
28 \cdot 6 \\
27 \cdot 2 \\
24 \cdot 6 \\
21 \cdot 2 \\
17 \cdot 5 \\
13.9 \\
10 \cdot 6 \\
7 \cdot 7 \\
5 \cdot 4\end{array}$ & $\left.\begin{array}{r}1 \\
1 \\
4 \\
1\end{array}\right\}$ & $\begin{array}{r}5.0 \\
\\
5.0 \\
7.7 \\
10.7 \\
13.5 \\
15.7 \\
16.8 \\
16.6 \\
15.4 \\
13.4 \\
10.9 \\
8.5 \\
6.2\end{array}$ \\
\hline $\begin{array}{l}\text { Daily } \\
\text { Average }\end{array}$ & $\begin{array}{r}15 \\
x^{2} 17\end{array}$ & 17 & $x_{10}^{18}=$ & 4.9 & $\begin{array}{r}1 \\
x^{2} 17\end{array}$ & 15 & $x_{12}^{2}$ & $911 \cdot 1$ \\
\hline
\end{tabular}

We must now test whether the theoretical efficiencies and occupation factors for different numbers of beds provided would have been achieved.

On the 312 weekdays in 1950, 6,165 beds were demanded, giving an average demand of $19 \cdot 8$. If 22 beds had been provided each day, 6,864 would have been made available altogether, and beds would have been immediately available for 5,839 patients. (This last figure is the sum of the total number of patients when the demand was less than
22 , plus 22 times the number of days with a demand of 22 or more).

Thus $\mathrm{E}=5,839 / 6,165=94 \cdot 7$ per cent;

$$
F=5,839 / 6,864=85 \cdot 1 \text { per cent. }
$$

The corresponding theoretical figures for mean demand 20, with 22 beds provided are:

$$
\begin{aligned}
& E=95 \cdot 1 \text { per cent.; } \\
& F=86 \cdot 5 \text { per cent. }
\end{aligned}
$$

In Table III, the observed E and F for two and four beds more than the mean daily demand are shown for each of the four distributions from the hospital data. Their theoretical equivalents are shown in brackets.

TABLE III

\begin{tabular}{|c|c|c|c|}
\hline Series & $\underset{\text { Provision }}{\text { Daily }}$ & E (per cent.) & F (per cent.) \\
\hline $\begin{array}{l}\text { Weekdays, } 1950 \\
\text { (Mean demand 19.8) }\end{array}$ & $\begin{array}{l}22 \\
24\end{array}$ & $\begin{array}{l}94 \cdot 7(95 \cdot 1) \\
97 \cdot 3(97 \cdot 6)\end{array}$ & $\begin{array}{l}85 \cdot 1(86 \cdot 5) \\
80 \cdot 2(81 \cdot 3)\end{array}$ \\
\hline $\begin{array}{l}\text { Weekdays, } 1951 \\
\text { (Mean demand 18.1) }\end{array}$ & $\begin{array}{l}20 \\
22\end{array}$ & $\begin{array}{l}93 \cdot 8(95 \cdot 0) \\
96.6(97 \cdot 6)\end{array}$ & $\begin{array}{l}85 \cdot 0(85 \cdot 5) \\
79 \cdot 5(79 \cdot 9)\end{array}$ \\
\hline $\begin{array}{l}\text { Weekdays, } 1952 \\
\text { (Mean demand 19.1) }\end{array}$ & $\begin{array}{l}21 \\
23\end{array}$ & $\begin{array}{l}94 \cdot 5(95 \cdot 1) \\
97 \cdot 0(97 \cdot 6)\end{array}$ & $\begin{array}{l}85.9(86 \cdot 0) \\
80.5(80.6)\end{array}$ \\
\hline $\begin{array}{l}\text { Sundays, 1950-2 } \\
\text { (Mean demand 13.9) }\end{array}$ & $\begin{array}{l}16 \\
18\end{array}$ & $\begin{array}{l}93 \cdot 1(94 \cdot 8) \\
95 \cdot 5(97 \cdot 8)\end{array}$ & $\begin{array}{l}80 \cdot 6(83 \cdot 0) \\
73 \cdot 5(76 \cdot 1)\end{array}$ \\
\hline
\end{tabular}

EFFICIENCY AND OCCUPATION FACTORS: HOSPITAL DATA

It will be noticed that in each case the theoretical model slightly overestimates $\mathrm{E}$ and $\mathrm{F}$ for any of the practical situations considered. This is due to the very long "tails" of the distributions shown in Table II, which are not sufficient to reject the hypothesis of a Poisson distribution using the usual $\chi^{2}$ criterion, but are definitely abnormal observations on this hypothesis. The discrepancy is most marked in the "Sundays 1950-2" distribution, where the demands of 30,31 , and 39 beds upset the model. Although it would be possible to take account of these using a different mathematical model, the simplicity of the results would be lost. It is considered preferable to use the Poisson model, and accept the limitation that the method will slightly overestimate $E$ and $F$ if such extreme demands occur.

\section{Discussion}

(a) The Lower Sunday Demand.-This is only partly explained by the fact that in an industrial area, the accident rate is lower when the factories, mines, and shipyards are closed, despite an increase in domestic and street accidents. Nor can the lower Sunday demand for emergency beds other than for accident cases be due to patients' reluctance to call a doctor on Sunday, as this would appear as a higher demand on Mondays than on other weekdays. 
The suggested reason is that while some emergency patients are in immediate need of a bed, there are others whose demand for an emergency bed can be deferred for a few days until the appropriate clinic is to be held.

(b) Seasonal Variations.-In hospitals where the population or the hazards fluctuate annually, it is reasonable to divide the year into seasons, and to base the provision of beds on the mean demand for the relevant season, as we have here separated the Sunday demand.

In the present investigation, there was no appreciable seasonal fluctuation in demand in 1950, but there was a significant increase in the last 4 months of 1951, and a decrease in the last 4 months of 1952. Many post hoc causes might be suggested for this, but at the time the trends were unexpected. For this reason, no account has been taken of these fluctuations in the calculations.

(c) Practical Considerations. - The average demand for a whole year cannot be known until the end of the year. A "moving average" of the previous 6 months gives an estimate of the mean demand for the coming month. For an area where there is a large seasonal fluctuation, the average demand for the previous six months of the relevant season should be used. When seasonal and Sunday averages have been worked out, the results of Section 2 should be applied to each season separately.

(d) Further Investigation.-As has been pointed out recently (Lancet, 1953), an annual increase in the demand for emergency beds due to acute respiratory disease or heart-failure precipitated by bronchitis occurs at regional-board hospitals, but is hardly noticed at all at teaching centres.

The mathematical model and its consequences have so far been tested only against data from a teaching hospital. It is intended to continue this investigation by collecting data from other types of hospitals serving other areas.

It has been assumed in this paper that an emergency case can be assigned to any vacant emergency bed. Alternatives to this simplifying assumption also remain to be considered.

\section{SUMMARY}

The problem of the number of hospital beds to be reserved for emergencies is considered.

A simple mathematical model of the demand pattern is suggested, and tested against hospital data.

It is found that any scheme for the provision of emergency beds should take into account constant seasonal differences, if any, including in particular any difference in the demand pattern on Sundays as compared with weekdays. When this is done, it is shown that for average daily demands of between 5 and 30 beds:

(i) Two more beds than the average daily demand should be provided to ensure a bed immediately available for 95 per cent. of emergency cases.

(ii) Four more beds than the average daily demand ensure a bed for 97.5 per cent. of cases.

The bed-occupation factors of these schemes are also studied.

I should like to thank Mr. N. T. J. Bailey for suggesting this problem, and the House Governor and Records Officer of the Royal Victoria Infirmary, Newcastle-uponTyne, for providing the data.

\section{REFERENCES}

Daley, A. (1953). Brit. med. J., 2, 243.

Lancet (1953), Leader, $2,975$.

Molina, E. C. (1942). "Poisson's Exponential Binomial Limit". Van Nostrand, New York. 